\title{
The Intersection of Plant Breeding, Human Health, and Nutritional Security: Lessons Learned and Future Perspectives
}

\author{
Bhimanagouda S. Patil ${ }^{1}$, Kevin Crosby, and David Byrne \\ Vegetable and Fruit Improvement Center, Department of Horticultural Sciences, Texas A\&M University, \\ 1500 Research Parkway A120, College Station, TX 77845 \\ Kendal Hirschi \\ Vegetable and Fruit Improvement Center, Department of Horticultural Sciences, Texas A\&M University, \\ 1500 Research Parkway A120, College Station, TX 77845; and USDA/ARS Children's Nutrition \\ Research Center, 1100 Bates Street, Houston, TX 77030
}

Additional index words. flavonoids, nutritional security, phytochemicals, sustainable

\begin{abstract}
In recent years, concerns about global, sustainable, and nutritional security have gained substantial momentum propelled by rapid increases in global population and food insecurity. Historically, plant breeding has played a key role in improving crop yield to keep pace with the rising global population; however, current plant breeding efforts focusing on increasing yield may need to be realigned toward nutritional security issues. Although traits affecting yield and disease resistance remain essential, emerging research highlights the importance of nutrition, flavor, quality, and enhanced healthpromoting properties in reducing food and nutritional impoverishment. We review plant breeding efforts to address nutritional impoverishment and the importance of consumer perception of flavor, nutrition, and quality. The Vegetable and Fruit Improvement Center (VFIC)'s interdisciplinary research related to "Foods for Health" in pepper, cantaloupe, citrus, carrot, peach, and plum provides specific examples of improvements in vegetable and fruit quality and health-promoting properties. We discuss historical perspectives, case studies, current programs, and a future outlook on the role of plant breeding in nutritional security. Our work focuses on the nexus of plant breeding, human health, and nutritional security as a foundation for future plant improvement strategies.
\end{abstract}

\section{WHY FOOD SECURITY AND NUTRITIONAL SECURITY?}

Food security is defined as "people at all times have access to sufficient, safe, nutritious food to maintain a healthy and active life" (FAO, 1996). The effort to improve food security faces many future challenges, including increasing population, climate changes, and water use issues. Almost all of the additional 3.0 billion people projected to inhabit our world by 2050 will reside in developing countries. To meet their dietary requirements, agricultural production needs to be increased by $70 \%$ (Bruinsma, 2009). In addition to a rising population, challenges such as water scarcity and climate change compound the effect and could result in severe food insecurity. Climate change is now a global concern with well-documented evidence indicating

Received for publication 22 Aug. 2013. Accepted for publication 19 Nov. 2013.

This paper was part of the colloquium "Advances in Breeding Vegetables and Fruits for Enhanced Nutritional Content" held 31 July 2012 at the ASHS Conference, Miami, FL, and sponsored by the Vegetable Breeding Working Group.

The authors would like to thank Dr. Ram M. Uckoo and Dr. G.K. Jayaprakasha for their valuable suggestions and constructive comments that greatly contributed to improving the quality of this manuscript. This project is based upon the work supported by the USDA-NIFA No. 2010-34402-20875, "Designing Foods for Health" through the Vegetable \& Fruit Improvement Center.

${ }^{1}$ To whom reprint requests should be addressed; e-mail b-patil@tamu.edu. severe adverse effects, including a biodiversity loss of greater than 100 species/year and $\approx 120$ million tons/year removal of atmospheric nitrogen by modern agricultural practices (Rockstrom et al., 2009). These climatic changes also significantly affect water use (Liu et al., 2013) as the water required to produce food will increase to $\approx 8,500$ to $11,000 \mathrm{~km}^{3} /$ year from the current $7100 \mathrm{~km}^{3} /$ year by 2050 (Rockström et al., 2010). These effects are not limited to specific nations but have a global impact. Therefore, in light of these projections, food security requires a sustainable global approach to overcome these challenges.

Food insecurity encompasses the inability to access adequate food calories and undernutrition, which can be caused by food and non-food reasons (Beddington, 2011). The inability to access food (hunger) causes $\approx 40$ million deaths, among which $33 \%$ are children. The FAO estimates that 925 million people (13.6\% of the world population) suffer from hunger, among which $88 \%$ are in sub-Saharan Africa and Asia-Pacific regions (Jachertz, 2012). Malnutrition accounts for more than one-third of all deaths worldwide in children younger than 5 years of age (Victora et al., 2010). The concept of food insecurity highlights the concept that health and survival require access to food providing both sufficient calories and necessary nutrition. Therefore, nutritional security is an integral part of food security (Afari-Sefa et al., 2012).

Tremendous efforts have been made to address the lack of food and nutritional security. For example, the U.S. Department of
Agriculture (USDA) food guide pyramid reflects emerging science in advocating the importance of balanced nutrition to help attain nutritional security. The diagram depicting the recommended daily intake of different foods for maintaining a healthy style has evolved from simple dietary guidelines in the year 1980 to a "Food Guide Pyramid" in 1992 and "MyPlate" in 2011. The current USDA dietary guideline, "MyPlate," recommends that consumption of fruits and vegetables account for at least $50 \%$ of the total food consumed in a meal. The recent emphasis on the consumption of fruits and vegetables is based on their lack of unhealthy saturated fats and their health-promoting role in providing essential vitamins, nutrients, and phytonutrients. Fruits and vegetables contain many classes of bioactive compounds such as flavonoids, limonoids, organic acids, carotenoids, anthocyanins, capsiacinoids, and tannins. Increasing evidence shows that these bioactive compounds have potentially multiple roles in preventing chronic diseases. However, genetic enhancement in fruits and vegetables has focused on improving yield, disease resistance, and pest resistance. The improvement of food security to improve human health requires a paradigm shift in plant breeding to integrate nutrition (DellaPenna, 1999). This will require coordination of scientists involved in plant breeding, human health, and nutritional sciences (Fig. 1).

Plant breeding for health-promoting properties. Plant breeding provides an effective strategy to increase the levels of healthpromoting bioactive compounds in the human diet. Bioactive compounds in fruits and 
vegetables vary significantly in both type and concentration among species and cultivars (Patil et al., 2009; Uckoo et al., 2011a). To increase the levels of bioactive compounds, advances in marker-assisted breeding have enabled plant breeders to screen large plant populations and select improved varieties rapidly and efficiently (Varshney et al., 2009). To increase the types of compounds, exploiting the potential of native, indigenous, and wild species to introduce unique bioactive compounds could feed into breeding programs to increase the types and levels of bioactive compounds in commercial cultivars (Patil et al., 2012). Table 1 illustrates breeding programs that increased the levels of bioactive compounds in specific crops.

For successful improvements in human health, plant breeders must also address consumer preferences. For example, although biotechnological approaches have been successful, consumers prefer traditional genetic with improved nutritional attributes (Colson and Huffman, 2011). Breeders should also consider taste and quality while breeding for nutritional benefits. These two parameters significantly impact the acceptance of fruits and vegetables. For example, increasing the levels of bioactive compounds that contribute to bitter tastes or astringency may not be an ideal approach. sition and levels of bioactive compounds for human health. A fundamental question that needs to be determined is what are the opapproaches and will pay more for products

Breeders must also optimize the compo-

timum levels of the bioactive compounds that need to be increased or decreased by breeding? Are the increased levels effective in preventing or curing nutritional deficiencies? The answers to these questions will require collaborative efforts among plant breeders, human health researchers, and nutritional scientists. Such collaborative efforts can lead to sustainability and nutritional security. For example, a dietary intervention study with orange sweetpotato containing higher levels of beta-carotene showed that sweetpotato consumption improved vitamin status in primary school children in Africa (van Jaarsveld et al., 2005). In another study, broccoli cultivars were hybridized with wild Brassica species to increase glucosinolates. The hybrids had 10fold higher glucosinolate levels and induced quinone reductase in vivo (Faulkner et al., 1998). Quinone reductase is a Phase II enzyme that plays a critical role in detoxification of potential carcinogens in the human body. Thus, translational science can improve human health through collaborative research among plant breeders, nutritionists, and health researchers.

Food and nutritional sciences/postharvest physiology. The seasonal nature and short shelf life of fruits and vegetables limit the consumption of fresh produce. However, processing of perishable fruits and vegetables into different food products can extend their shelf life from months to years (MartinBelloso and Fortuny, 2011). Designing proper packaging and storage conditions are essential to maintain the levels of bioactive compounds.

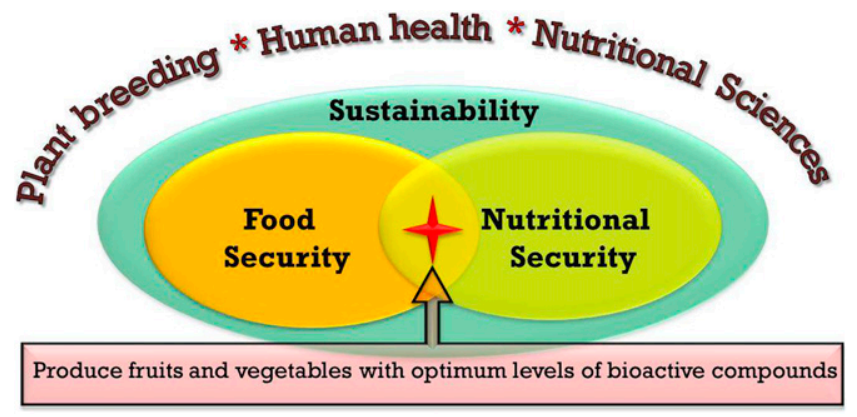

Fig. 1. An integrated approach for achieving sustainable food and nutritional security.
Developing processing conditions and implementing innovative technologies could help minimize the degradation of bioactive compounds (Uckoo et al., 2013b). Innovative processing technologies have enabled transcontinental trade of fruits and vegetables (Leong and Oey, 2012). Consumers are now able to access several produce commodities containing a wide array of bioactive compounds that were not accessible earlier. Understanding the mechanisms required to retain bioactive compounds in different food matrices is also important (Uckoo et al., 2012a).

Food processing techniques must also avoid nutritional degradation, including naturally occurring toxins, drug interactions, and pathogen growth. Although consumption of most fruits and vegetables does not produce adverse effects, certain naturally occurring compounds may have undesirable effects, including toxicity (Murakami and Ohnishi, 2012). Similarly, other challenges such as drug interaction, rate of metabolism, and gut microbial interactions need to be ascertained for various food products. These technologies also require strategies to control and reduce the microbial bioburden. Significant strides have been made in this direction by the food and nutritional sciences in the past few decades. Processing fruit juices with non-thermal processing conditions such as high-pressure processing, ultraviolet pasteurization, and pulse electric field processes that reduce microbial contamination and help prevent degradation of vitamin $\mathrm{C}$ and carotenoids are now being applied by commercial fruit manufacturers (Uckoo et al., 2013b; Wootton-Beard and Ryan, 2011).

Biofortification. Plant biofortification, increasing the bioavailable concentration of a nutrient in foods, has been cited as a preeminent global challenge by a panel of the world's foremost economists (Gilligan, 2012; Hirschi, 2009; White and Broadley, 2009). Furthermore, the panel predicted tremendous benefits compared with costs associated with developing biofortification technology. Several strategies, determined by the target crop, are being implemented for biofortification, including mineral fertilization, conventional

Table 1. Impact of traditional and biotechnology-assisted breeding of crops for higher levels of bioactive compounds in fruits and vegetables.

\begin{tabular}{|c|c|c|c|c|c|}
\hline Crop & Bioactive & Technique & Initial level & Modified level & Reference \\
\hline Tomato & Monoterpene (Linalool) & $\overline{\mathrm{BT}}$ & 0 & $187 \mathrm{ng} \cdot \mathrm{g}^{-1} \mathrm{FW}$ & Lewinsohn, et al., 2001 \\
\hline \multirow[t]{2}{*}{ Tomato } & Carotenoid & BT & 58.3 & $132.80 \mu \mathrm{g} \cdot \mathrm{mL}^{-1}$ & Davuluri et al., 2005 \\
\hline & Flavonoid & & $70-80$ & $240-260 \mu \mathrm{g} \cdot \mathrm{g}^{-1} \mathrm{DW}$ & \\
\hline Onion & Total flavonols & TR & $79-431$ & $228-675 \mathrm{mg} / \mathrm{kg}$ & Smith et al., 2003 \\
\hline \multirow[t]{2}{*}{ Pepper } & Ascorbic acid & TR & $328-1781$ & $2078.93 \mu \mathrm{g} \cdot \mathrm{g}^{-1} \mathrm{FW}$ & Butcher et al., 2013 \\
\hline & Capsaicin & & $6.08-285$ & $320.45 \mu \mathrm{g} \cdot \mathrm{g}^{-1} \mathrm{FW}$ & \\
\hline Potato & Anthocyanins-(Peonidin-Pelargonidin) & BT & $5-50$ & $40-290 \mathrm{mg} / 100 \mathrm{~g} \mathrm{DW}$ & Stobiecki et al., 2003 \\
\hline Potato & Carotenoids & BT & 4.67 & $12.27 \mathrm{mg} \cdot \mathrm{g}^{-1} \mathrm{DW}$ & Diretto et al., 2006 \\
\hline Potato & Ascorbic acid & BT & 1.1 & $3.0 \mu$ moles $\cdot g^{-1}$ & Hemavathi et al., 2010 \\
\hline Potato & Zeaxanthin & BT & 0.3 & $40 \mu \mathrm{g} \cdot \mathrm{g}^{-1} \mathrm{DW}$ & Römer et al., 2002 \\
\hline Broccoli & Glucosinolate & TR & 7.1 & $154 \mu$ moles $\cdot g^{-1} \mathrm{DW}$ & Faulkner et al., 1998 \\
\hline Broccoli & Glucosinolate & TR & 3.5 & $19.0 \mu$ moles $\cdot \mathrm{g}^{-1} \mathrm{DW}$ & Sarikamis et al., 2006 \\
\hline Melon & Beta-carotene & TR & 0.76 & $2.04 \mu \mathrm{g} \cdot \mathrm{mL}^{-1}$ & Haponik et al., 2004 \\
\hline
\end{tabular}

$\mathrm{BT}=$ biotechnology; $\mathrm{TR}=$ traditional breeding; $\mathrm{FW}=$ fresh weight; $\mathrm{DW}=$ dry weight. 
breeding, and transgenic approaches. Fertilization efforts are often simple; however, the application of fertilizers containing essential mineral micronutrients is complicated by several factors such as the application method, mineral mobility in the plant, and its accumulation site. Plants often show genetic variation in nutrient content, which then allows breeding programs to improve the levels of minerals and vitamins in crops (Hirschi, 2009). There are few regulatory constraints on plant breeding; however, breeding strategies can be limited by the genetic variation present in the crop germplasm. Alternatively, new traits can be introduced directly into commercial varieties by mutagenesis. In crops with limited genetic variation in nutrient content, transgenic approaches can be a valid alternative. Indeed, modern genomics tools that provide a systems-level understanding of the effect of genotype on nutrient contents can potentiate transgenic approaches. Nutritional genomics studies the relationship among genomes, nutrition, and health (Brigelius-Flohe and Joost, 2006; DellaPenna, 1999) and recent biofortification efforts have been driven by the ability to rapidly identify and characterize gene function and then use these genes to engineer plant metabolism (Christou and Twyman, 2004).

Integration of plant breeding and health sciences. Biofortified foods offer a potentially powerful intervention that targets the most vulnerable people (resource-poor women, infants, and children). However, few studies have measured the most important parameter for success: are these improved foods actually functional foods that prevent or cure nutritional deficiencies (Hirschi, 2009; Li et al., 2013; Powell, 2007; Yang et al., 2012). On the one hand, it can be prudent to wait for bioavailability studies; for example, the initially engineered versions of golden rice had very little beta-carotene (Nestle, 2001). On the other hand, how can so much time and effort be invested in this technology without performing fundamental studies of nutritional benefits? Unfortunately, the lack of nutritional assessment in biofortified foods is the norm rather than the exception. Different carotenoid-enriched foods (DellaPenna, 2007) and crops enriched with other micronutrients such as vitamin E (Ajjawi and Shintani, 2004) and folate (Bekaert et al., 2008) are further examples where the genetically modified foods have not been adequately assessed at the nutritional level. A notable exception is the study of integrated plant breeding and nutritional studies of the Orange Fleshed Sweet Potato (OFSP) rich in beta-carotene, which was developed to address vitamin A deficiency in rural subSaharan Africa. The study included evaluation of adoption, adaptive testing, and breeding of OFSP followed by human intervention studies evaluating the effect of dietary intake of OFSP on child vitamin A dietary intake and serum retinol (Low et al., 2005). This type of approach serves as a paradigm for the integration of plant breeding and human nutritional studies.
Advent of the "superfruit" and "supervegetable." As consumers learn more about the benefits of fruit and vegetable consumption for human health, the demand for healthier foods increases. Proper diet can contribute to the prevention of cardiovascular disease, vision problems, obesity, arthritis/joint pain, and high cholesterol. As a result of enhanced consumer awareness of this, the health benefits of foods provide one of the major driving forces of the world food market (Dillard and German, 2000; Sloan, 2006). Fruits and vegetables have been in the forefront of the food for health movement as a result of the increasing awareness among the consumers on the healthy living (Wargovich et al., 2012). Health benefits differ among crops and bioactives from certain crops protect against various chronic diseases such as cancer and cardiovascular disease (Wargovich et al., 2012). This work has lead to superfruits, which are thought to have exceptional health benefits. Although the best known are blueberries, pomegranate, and exotics like acai, noni fruit and mangosteen, many of our temperate fruits such as apples, plums, prunes, blackberries, raspberries, strawberries, grapes, black currants, persimmons, oranges, grapefruits, and cherries have also been proclaimed superfruits. Similarly, vegetables such as tomatoes, peppers, carrots, broccoli, and sweetpotatoes have been considered to have higher levels of bioactive compounds than other vegetables (Jeffery et al., 2003; Lee et al., 2005).

"Super," which clearly denotes superior health benefits, has been an effective marketing tool in promoting the consumption of specific a fruit or vegetable (Byrne, 2012; Wargovich et al., 2012). Nevertheless, the consumption of fruits and vegetables in general is still approximately half of the recommended levels despite concerted government efforts since the 1990s (Pollack and Perez, 2008; Wells and Buzby, 2008). This presents an opportunity for plant breeders. Because fruit and vegetable consumption has not increased, another approach would be to enhance the health benefits of the foods that are consumed. As has been seen with the healthoriented marketing of superfruits and supervegetables, it is possible to increase the consumption of a specific fruit or vegetable by touting its high antioxidant capacity. The next step of this process would be to develop cultivars with improved flavor, taste, and enhanced levels of bioactive compounds.

What would it take to breed a variety of fruit or vegetable significantly enhanced for a nutrient or phytonutrient? Breeding for enhanced health properties is a goal of many breeding programs (Cantiìn et al., 2009; Connor et al., 2002a, 2002b, 2005a, 2005b, 2005c; Kappel, 2005; Khanizadeh et al., 2007; McDougall et al., 2005; Moyer et al., 2002; Vizzotto et al., 2007; Vorsa and Polashock, 2005). However, multiple parameters must be considered in the choice of crop and target compounds. The crop must show good phenotypic variation in compound levels, and this variation must be heritable. Moreover, traits must be carefully selected to provide health benefits without decreasing agronomic performance or quality. For a new variety to be successful, it must satisfy the grower, the marketer, and the consumer. Thus, a new health-enhanced fruit variety will need to be productive, easy to grow and harvest, have good post-harvest handling characteristics, and be attractive, flavorful, and easy to eat. These traits are complex and are in turn divided into dozens of well-defined traits that the breeder selects for or against(Wargovich et al., 2012). In addition to plant breeding, agronomic practices such as high-technology cultivation in computer-controlled greenhouses with hydroponic and aeroponic systems have enabled producers to modulate the levels of bioactives. These strategies, along with emerging evidence on health benefits, could clearly pave the way for breeding a supervegetable or fruit.

Phenotypic variation in levels of healthpromoting compounds. In some cases, generation of a superfruit simply involves identification of a cultivar with high levels of bioactive compounds. For apple, peach, plum, and blueberry, there is a wide range in measured antioxidant capacity irrespective of the methodology used to examine total phenolics and anthocyanins (Wargovich, 2012). Although commercial cultivars showed significant differences, in some studies that examined breeding materials and other non-commercial germplasm, the range of antioxidant capacity, total phenolics, and/or anthocyanins measured was greatly enlarged (Cevallos-Casals et al., 2006; Connor et al., 2002b; Moyer et al., 2002; Vizzotto et al., 2007). Thus, it is clear that there is genetic variation within crops. Currently, there are genotypes within the commercial cultivar mix that have higher levels of antioxidants that could be promoted as such; this type of marketing has already been initiated. Furthermore, in the case of peaches, plums, and blueberries, there are also genotypes outside the commercial mix of cultivars that have even higher levels of antioxidants than commercial germplasm, indicating the possibility of increasing the levels even more.

However, the health-promoting benefits of superfruits may involve interactions of multiple bioactives. This may generate emergent properties that cannot be measured by simple quantification of a specific compound or may identify specific classes of bioactives that correlate with activity. Therefore, in addition to examining the variation in general antioxidant activity or levels of specific classes of antioxidants (total phenolics and anthocyanins), some studies have examined the relationship of genotypes and bioactivities. For example, fruit varieties have been tested for their ability to inhibit proliferation of cancer cells, the inhibition of low-density lipoprotein oxidation and other bioactivities, in strawberries (Meyers et al., 2003), apples (Thompson et al., 2009; Wolfe et al., 2003; Yoshizawa et al., 2005), blueberries (Yi et al., 2005), peaches, plums (Byrne et al., 2009; Chang et al., 2000), and other fruits. These studies have shown that, as was seen with 
antioxidant activity and the levels of bioactives, genotypes within a crop differed in their bioactivity toward cancer growth or cardiovascular disease development as measured by various in vitro assays. Another crucial observation is that neither antioxidant activity nor total phenolics or anthocyanins consistently correlated with these various bioactivities (Byrne et al., 2009; Liu, 2003, 2004; Meyers et al., 2003; Sun et al., 2002). This does not indicate that antioxidant activity is unimportant in preventing these chronic diseases, but rather that there are other mechanisms by which these diseases are regulated and that the bioactives within a fruit work additively and synergistically to control disease development (Liu et al., 2005).

Genetic basis of phenotypic variation. Plant breeding can further improve the health-promoting properties of a plant variety. Many studies have examined the genotypic variation in antioxidant activity and the levels of bioactives in fruits. Some studies have examined annual variation (Lata, 2007; Lata et al., 2005, 2009; Wojdyło et al., 2008) and variation between locations (Connor et al., 2002a, 2005a, 2005b, 2005c; Prior et al., 1998). In general, although the cultivar effect was large, the antioxidant activity and bioactive concentrations seen among cultivars varied from year to year and among locations, presumably as a result of differences in climatic, cultural, edaphic, or other conditions. Breeding studies with blueberry (Connor et al., 2002b) and red raspberry (Connor et al., 2005b) estimated the narrow-sense heritability as moderate for antioxidant activity and total phenolic content and moderate to high for total anthocyanin content. In red raspberries, the narrow-sense heritability estimates varied from 0.45 to 0.78 for individual anthocyanins. The anthocyanin with the highest concentration (cyanidin 3-sophoroside) had a heritability of 0.56 . These moderate to high heritabilities indicate that good progress can be expected in the breeding of blueberry and red raspberry for higher antioxidant levels (Connor et al., 2005c). In these crops, the year accounted for little of the variance, whereas the importance of the genotype $\times$ year effect differed between the crops with only blueberry showing a significant interaction. Although the most common interest in breeding for health is perhaps increasing the levels of secondary metabolites, in grapefruit, the recent focus has been to decrease the levels of furanocoumarins. These unique biologically active compounds are known to have drug interaction activities (Bailey et al., 1998). Most recently breeding efforts have been focused toward selection of low furanocoumarin seedless grapefruit cultivars (Chen et al., 2011).

In peach, a study of 15 progenies over 3 years indicated that the cross-variation explained $\approx 20 \%, \approx 34 \%$, and $\approx 16 \%$ of the phenotypic variation of antioxidant activity, total phenolics, and total anthocyanins, respectively. In this study, the variation resulting from year or cross $\times$ year was not significant (Cantiìn et al., 2009). This study used commercial germplasm, which is limited in the amount of antioxidant activity, total phenolics, and total anthocyanins as compared with the breeding more genetically diverse germplasm available (Wargovich et al., 2012). Thus, it is likely that the genetic component for these traits would be higher if breeding used this high-antioxidant germplasm. Although this would facilitate rapid progress in boosting the antioxidant/bioactive levels of peaches, further breeding would be required, because these materials are lacking in many important commercial traits. One potential problem could be that a trait for a desired phytonutrient profile is pleiotropic of genetically linked to negative agronomic phenotype.

How do you select target traits? Unfortunately, despite numerous evidences that identify extracts or specific compounds that affect the development of chronic diseases, it is not clear which chemicals or what levels of these chemicals should be the target of breeding programs. Studies using a whole class of compounds with in vivo models (Shabrova et al., 2011) could be useful in identifying classes of compounds for genetic enhancement. Multiple breeding programs have explored the levels of bioactives, antioxidant activity, and other bioactivities among the genotypes in their breeding germplasm (Baranski et al., 2012; Wargovich et al., 2012). These results, combined with a few breeding studies, clearly indicate that there is sufficient genetic variability to develop cultivars with increased levels of antioxidant activity, total phenolics, and anthocyanins.

Epidemiological studies have indicated that the lack of fruit and vegetable consumption increases risk for cancer and cardiovascular disease (Chong et al., 2010; Danaei et al., 2005). It has frequently been asserted that the consumption of higher levels of antioxidants is good for one's health and many products are sold using this claim. Nevertheless, we lack definitive proof that antioxidant supplements reduce the development of chronic disease (Amiot, 2008). In the case of cardiovascular disease, the evidence supports the assertion that fruit with higher total phenolics reduces the risk of cardiovascular disease more than low phenolic fruit (Chong et al., 2010). However, the bulk of this work has been done in cell culture model systems, which serve to identify potentially useful chemicals and study their mechanisms of action but, as a result of bioavailability and other issues, cannot establish the effective levels in animal model systems or for use in humans. Even work with small animal models, although better than a cell culture protocol, does not necessarily translate well to a human system (Finley, 2005). Furthermore, there are potential synergistic interactions among various bioactives, which makes the situation more complex (Liu, 2004; Milde et al., 2007).

More research is needed to identify target bioactives and the levels required for a beneficial effect on long-term health and the prevention of chronic diseases. These studies need to compare cultivars with varying levels of bioactives as well as specific individual or combinations of bioactives in animal models and human clinical trials to identify the key targets for the development of truly health enhanced cultivars of fruit.

\section{RESEARCH AT THE VEGETABLE \& FRUIT IMPROVEMENT CENTER ADDRESSES FOOD AND NUTRITIONAL IMPOVERISHMENT THROUGH THE FOODS FOR HEALTH PROGRAM:}

\section{Isolation, characterization, and analysis of health-promoting compounds}

Unraveling the science of the health benefits of fruits and vegetables is important to both consumers and the produce industry. In the past two decades, many plant bioactive compounds with antimicrobial, insecticidal, cytotoxic, and anticancer activities have been discovered (Kaul et al., 2012; Kim et al., 2012; Regnault-Roger et al., 2012; Šmejkal, 2013). To provide proof of concept for "consumption of fruits and vegetables help prevent specific chronic diseases" is a daunting task, which requires isolation of the bioactive compounds present in fruits and vegetables and systematic evidence of their bioactivity. Although significant progress has been made in this direction, tremendous opportunities and challenges still exist. The technological advances in chromatography in recent years have significantly reduced the time, labor, and solvents required for isolation of bioactives at high purity (Uckoo et al., 2012b). Development of large-scale isolation methods is also important to determine their activities in in vivo studies. Several bioactive compounds such as limonoids (Jayaprakasha et al., 2008), furocoumarins (Girennavar et al., 2007), flavonoids (Raman et al., 2004), monoterpenes (Jayaprakasha et al., 2013), and sterols (Jayaprakasha et al., 2007; Vikram et al., 2013) were isolated from various parts of fruits, including industrial byproducts (Uckoo et al., 2011b, 2013a). These compounds were further evaluated for their bioactivities by in vitro and in in vivo studies to elucidate structure-activity relationships and help understand the mechanism of action (Jayaprakasha et al., 2009, 2012a, 2012b; Kim et al., 2011; Perez et al., 2009).

Furthermore, health-promoting compounds from fruits and vegetables, either as pure compounds or as standardized extracts, have unmatched chemical diversity and thus can provide opportunities for exploring novel biological activities (Chidambara et al., 2012; El-Houri et al., 2012; Kim et al., 2012). As a result of an increasing demand for chemical diversity, programs screening compounds from fruits and vegetables are growing rapidly throughout the world. Extraction is the most important step in the analysis of plant constituents. Our group has optimized several methods for the extraction and quantification of bioactive compounds including flavonoids (Chebrolu et al., 2011), ascorbic acid (Uckoo et al., 2011a), limonoids (Jayaprakasha et al., 2011; Vikram et al., 2007), carotenoids (Jayaprakasha and Patil, 2010), L-citrulline (Jayaprakasha et al., 2011), and glucarate (Perez et al., 2008) from various fruits and 
vegetables. The analysis of bioactive compounds involves application of chromatographic techniques such as high-performance liquid-chromatography and thin layer chromatography (TLC) as well as nonchromatographic techniques such as immunoassay and Fourier Transform Infra-Red (Rohman et al., 2011). Volatile components can be quantified and identified by gas chromatography (GC), GC-mass spectroscopy, and GC-infrared detection. The wide range of spectroscopic techniques such as ultraviolet, infrared, or GCmass spectroscopy, liquid chromatographymass spectroscopy, nuclear magnetic resonance, and mass spectroscopy form the backbone of modern structural elucidation studies. Before the availability of such advanced techniques, ambiguities existed in the determination of structures of bioactive compounds. Spectroscopic determination also requires familiarity with the scientific literature; chromatographic isolation is only warranted for unknown or unavailable compounds (Brodbelt et al., 2006; Jayaprakasha et al., 2003; Vikram et al., 2007). Nuclear magnetic resonance (NMR) spectroscopy and high-resolution mass spectra provide feedback about the molecular structure of atoms in an extract (Jayaprakasha et al., 2011). NMR is a particularly powerful tool in this regard and recent advances have substantially increased its ability to quantify individual constituents (Bharti and Roy, 2012; Corcoran and Spraul, 2003). Therefore, analysis of individual components in a complex mixture and/or fruit and vegetables is important to understand the significance of bioactive compounds in human health.

\section{Plant breeding to provide nutritional security}

Peppers. In the Mayan and Aztec civilizations, wild pepper fruits were once used for their medicinal properties to treat problems associated with asthma, the common cold, coughing, and sore throats (Marinelli and Hanson, 1999). Also, members of the Tukano tribe in Colombia used peppers to relieve discomfort from hangovers, and members of the Teenek (Huastec) Indians of Mexico used peppers to heal infected wounds (Marinelli and Hanson, 1999). Current biomedical research has continued this interest in peppers. Conforti et al. (2007) examined different stages of pepper fruit maturity (immature green, green, and red hot peppers) to determine their effect on free radicals. Peppers at the small green stage of maturity had the highest radical-scavenging activity (IC50 of $129 \mu \mathrm{g} \cdot \mathrm{mL}^{-1}$ ) and methanol extracts of red peppers had the highest antioxidative potency (IC50 of $3 \mu \mathrm{g} \cdot \mathrm{mL}^{-1}$ ) (Conforti et al., 2007). This trend was verified by Howard et al. (2000), who found that the concentrations of different antioxidants increase as the fruit matures and that genetics and environment can dramatically affect bioactive concentrations in peppers. Ascorbic acid and flavonoid levels varied by as much as 60 -fold between lines and more than 6-fold between distinct production environments (Butcher et al., 2012; Lee et al., 2005). Thus, peppers have ample genetic variation and genotype $\times$ environment interactions to be exploited in breeding cultivars with enhanced nutritional values. Butcher et al. (2012) and Lee et al. (2005) have released two pepper cultivars with higher carotenoid levels than commercial cultivars: TAM Mild Habanero and Dulcito Jalapeño with enhanced beta-carotene and zeaxanthin, respectively (Crosby et al., 2005a, 2007). Currently, Crosby is developing pepper lines with elevated flavonoid levels. Some Texas A\&M University (TAMU) sweet pepper breeding lines have been developed with total quercetin and luteolin concentrations of more than $600 \mu \mathrm{g} \cdot \mathrm{g}^{-1}$, which is up to 10 -fold higher than most widely grown commercial bell pepper cultivars (Crosby et al., 2007). In addition, vitamin $C$ levels of more than $4000 \mu \mathrm{g} \cdot \mathrm{g}^{-1}$ have been detected in some TAMU small, sweet wax pepper lines (Crosby et al., 2005b). Furthermore, a bell pepper ('Tropic Bell' with higher ascorbic acid at the green maturity stage than commercial cultivars has also been released (Crosby et al., 2005b).

Melon breeding. The species Cucumis melo L. is divided into six horticultural groups based on diverse fruit and vine characteristics (Robinson and Decker-Walters, 1997). The great genetic diversity within this species is valuable for identification of genotypes high in beneficial compounds. However, there is a paucity of published information on genetic variation for fruit bioactive traits in melon (Cucumis melo L.). USDA statistics suggest that cantaloupe and honeydew melons are potentially good sources of vitamin $\mathrm{C}$ and beta-carotene but do not address potential variation in these compounds across cultivars or horticultural groups (Adams and Richardson, 1981). Variation in beta-carotene, vitamin C, and folate levels among different cantaloupe varieties has been demonstrated by several studies. Lester and Turley (1990) evaluated 19 different cantaloupe varieties for betacarotene levels at harvest and found significant variation, because concentrations ranged from 3203 IU to 5000 IU per fruit in different cultivars. In a second study, Lester and Eischen (1996) found significant variation for betacarotene content of mature cantaloupes among six varieties and that melons grown on silty clay loam had significantly higher levels of beta-carotene than in melons grown on fine sandy loam. Ascorbic acid and folate levels were also found to vary in honeydew melons based on both cultivar and field soil texture differences (Lester and Crosby, 2002). Similarly, melon ascorbic acid concentrations at Weslaco, TX, demonstrated a 3-fold difference between highest and lowest entries (Crosby et al., 2006). This represents substantial genetic variation considering that environmental parameters and growing conditions were presumably quite similar within the small field plots. The difference in vitamin $\mathrm{C}$ concentrations between the highest and lowest entries at Uvalde was even greater at $320 \mathrm{vs.} 75 \mu \mathrm{g} \cdot \mathrm{g}^{-1}$ suggesting a genotype $\times$ environment interaction is important in determining bioactive levels and underscores the importance of evaluating breeding lines in multiple locations and seasons.

The melon breeding program at the VFIC focuses on improving fruit quality to meet the demands of consumers and producers. The importance of melons in the human diet, coupled with their naturally high levels of vitamins, makes them ideal delivery systems for beneficial bioactives. Melons can provide vitamin $\mathrm{C}$, beta-carotene, potassium, calcium, sugars, and folate. Muskmelons are an excellent source of both vitamin $\mathrm{C}$ and beta-carotene (provitamin A). Among the top 10 most consumed fruits in the United States, muskmelons are the only ones that provide the recommended daily allowance of both of these vitamins (Lester, 1997). The stability of betacarotene concentration over time is very high, which makes selection for this compound more reliable (Lester and Bruton, 1986). In addition, there is a good correlation between levels of beta-carotene and desirable orange flesh color (Lester and Turley, 1990), which provides selection and marketing advantages. Genotypic and environmental effects on betacarotene levels have been observed in fieldgrown fruit under commercial production practices. Some melon cultivars such as TAM Uvalde and Mission produced consistent beta-carotene and ascorbic acid levels across environments, but others did not (Crosby et al., 2006). Vitamin C is very susceptible to degradation over time or by at high temperatures. Therefore, fresh melon consumption will deliver the highest concentrations of this important compound.

Carrots. Carrots also have great potential for delivering human health-related compounds. Beta-carotene has been increased dramatically over the past 50 years in both processing and fresh market carrot cultivars (Just and Simon, 2004). More recently other important antioxidant compounds have been identified and enhanced in carrot germplasm, including anthocyanins and lycopene. The carrot breeding program at the VFIC has developed the purple 'BetaSweet' (higher anthocyanins) cultivar and other colored carrots with specific bioactives such as lycopene (Lazcano, 1999). Over the last few years, a great deal of progress has been made in improving the taste, appearance, and betacarotene content of 'BetaSweet' carrots. To increase the portability of the 'BetaSweet' carrots, minimally processed carrots cut into coin shapes were evaluated for changes in carotenoid, anthocyanin, and sugar contents during 4 weeks of cold storage at 2 or $4{ }^{\circ} \mathrm{C}$, simulating the transportation and marketing period. The study concluded that the changes in quality of 'BetaSweet' carrots were minimal or negligible during the commercial marketing period of 2 weeks if the product was handled and displayed at $4{ }^{\circ} \mathrm{C}$ or below (Lee et al., 2011). Furthermore, a translational research study was conducted feeding 8 ounces of fresh 'BetaSweet' or 'Balero' orange carrot juice to subjects recovering from breast cancer and measuring plasma total carotenoid concentrations, which demonstrated that total plasma carotenoids increased by 1.65 and 
$1.38 \mu \mathrm{mol} \cdot \mathrm{L}^{-1}$ for 'BetaSweet' or 'Balero' carrot juice, respectively. These results also suggest daily intake of fresh carrot juice is a simple and effective approach for increasing plasma total carotenoids and in turn reducing oxidative stress, but not inflammatory markers, in women previously treated for breast cancer (Butalla et al., 2012). High lycopene carrots have been developed by commercial seed companies ('Atomic Red'), but most red carrots must be cooked to remove undesirable terpenoid-related flavors. Sweeter or less bitter carrots with high lycopene levels would be welcome additions to both fresh and frozen carrot markets.

Tomatoes. Tomatoes botanically a fleshy berry, have been the focus of more breeding activity than any other vegetable, and are a potentially excellent source of lycopene and other beneficial bioactives. High lycopene processing and fresh-market tomatoes have been developed over the last 30 years, but other key bioactives such as ascorbic acid, vitamin E, phenolic compounds, and amino acids have received much less attention. Recently, high anthocyanin cultivars have been developed and other potential phenolic compounds are being investigated (Mes et al., 2008). Tomato germplasm for ascorbic acid content has considerable genetic variation. In addition, the processing industry has made substantial efforts to breed for higher levels of organic acids and sugars. These may be important components in the synthesis of beneficial bioactives and thus may enhance the potential to develop higher ascorbic acid and carotenoids in fresh-market cultivars. Tomato germplasm with higher chlorophyll retention, a single gene trait, may also provide good candidates to improve tocopherol concentrations. Many heirloom cultivars have this trait and appeal to the sustainable and organic fresh-market sectors.

\section{Biofortification of vegetables with calcium for increased uptake}

A collaboration between the Vegetable and Fruit Improvement Center and health scientists. Calcium $(\mathrm{Ca})$ is an essential nutrient for bone development in children, but according to the USDA, seven of 10 boys and nine of 10 girls do not consume adequate levels of $\mathrm{Ca}$ (Ross et al., 2011; Uusi-Rasi et al., 2013). The dietary reference intake for $\mathrm{Ca}$ was set at levels associated with desirable retention of body $\mathrm{Ca}$ because high bone density decreased the incidence of bone fractures. Calcium provided to bones early in life helps to determine how well they will hold up later in life (Abrams and Strewler, 2007; Huncharek et al., 2008). Bone undergoes continuous remodeling with constant resorption (breakdown of bone) and deposition of Ca into newly deposited bone (bone formation). In healthy young people, the rate of bone mineral acquisition parallels the rate of linear growth. Gains in bone minerals are most rapid between 11 and 14 years in girls and 14 to 17 years in boys, following peak height velocity by a year (Bachrach, 1999). In aging adults, particularly among postmenopausal women, bone breakdown exceeds its formation, resulting in bone loss and increasing the risk of osteoporosis.

Increasing $\mathrm{Ca}$ intake in children provides an investment in our collective future, because osteoporotic fractures are becoming a major public health problem in the Western world (Bachrach, 2001; Verkler, 2006). The estimated cost is $\$ 10$ to $\$ 20$ billion annually in the United States. As populations age throughout the world, the costs worldwide can only increase, and estimates are staggering. Within 50 years, the cost of hip fractures in the United States may exceed $\$ 240$ billion. These health problems affect the elderly, but the bone bank for adulthood is acquired during the teenage years. Unfortunately, even seemingly healthy children and adolescents appear to be falling short of optimal bone health because of current diet and exercise trends. The National Osteoporosis Foundation suggests that, for most people, the disease is largely preventable and promotes five steps to prevent osteoporosis, the first of which is to get your daily recommended amounts of $\mathrm{Ca}$ and vitamin $\mathrm{D}$.

The foundation is quick to point out that no one step is enough to prevent osteoporosis. For example, Ca consumption is important, but other nutrients can also influence bone health; these key nutrients include vitamin $\mathrm{D}$, vitamin $\mathrm{K}$, salt, homocysteine, vitamin B-12, protein, and fatty acids and fruit and vegetable consumption (Atkinson et al., 2008; Greer and Krebs, 2006). Other research has questioned whether increasing $\mathrm{Ca}$ intake through diet or supplements benefits children's or young adults' bones (Lanou, 2006; Lanou et al., 2005). This research argues that public health would be better served by researching how other dietary and lifestyle factors affect children's bones. They point to promising areas include the effect of regular exercise, vitamin D status, and increasing fruit and vegetable consumption. In this work we are establishing novel means of delivering more $\mathrm{Ca}$ into consumers' diets using $\mathrm{Ca}$-enhanced vegetables.

Calcium in foods, fortification, and supplements. Dietary $\mathrm{Ca}$ derives from multiple sources, but each of these $\mathrm{Ca}$ sources has limitations. Many foods contain $\mathrm{Ca}$, but dairy products are the most significant source (Weaver et al., 1999). Milk and dairy products such as cheeses contain an efficiently absorbed form of $\mathrm{Ca}$. However, consumers do not drink enough milk or consume adequate amounts of dairy products. Lactose intolerance, or the perception of intolerance, affects between 30 and 50 million Americans and thus limits consumption (Carroccio et al., 1998; Matlik et al., 2007). Public awareness of the dangers of high-fat diets can also lead well-meaning parents to serve their children fewer Ca-rich dairy foods. Teenagers also often perceive milk as a "child's" drink and consumption of soft drinks crowds out more nutritious beverages such as milk.

Calcium is also added to food products such as breads and orange juice to make them a significant source of Ca. Dietary supplements are also an effective means of delivering $\mathrm{Ca}$ to consumers. However, among certain groups, lack of awareness of malnutrition and low consumer demand for fortified foods thwart worldwide use of this technology (Darnton-Hill and Nalubola, 2002; Program, 2006). In affluent markets, $\mathrm{Ca}$ fortification of food and beverage products has occurred across a wide spectrum of products including, for example, orange juice. Calcium fortification of orange juice delivers almost one-third of the daily Ca requirement in a single serving. Unfortunately, in developing countries, the distribution systems are not developed and regulatory systems are often not in place to successfully implement this technology. Like fortification efforts, Ca supplements may not always work (Martin et al., 2007; Merrilees et al., 2000; Prentice, 2004; Winzenberg et al., 2006). Half of all consumers in the United States use supplements but frequently these are not properly used. For example, $\mathrm{Ca}$ carbonate tablets need to be taken with a meal so that stomach acid can facilitate absorption, but Ca citrate tablets do not have this limitation. Calcium supplements will work for informed and affluent consumers but will be less likely to succeed in disadvantaged areas.

Green leafy vegetables such as broccoli and bok choy are also good sources of $\mathrm{Ca}$. However, despite aggressive public information campaigns, consumers do not eat enough vegetables, especially vegetables high in dietary $\mathrm{Ca}$ (Dawson-Hughes, 2006; Seeman et al., 2007; Weaver et al., 1999). A national fruit and vegetable initiative, built on the " $5 \mathrm{~A}$ Day" campaign, is underway. The "Fruits and Veggies-More Matters" initiative will continue the goal of increasing awareness of the need for people to consume these foods $(<\mathrm{http}: / /$ www.fruitsandveggiesmorematters.org $>$ ). Our work is geared toward increasing the Ca content in popular foods like lettuce and carrots that are not usually associated with high levels of dietary $\mathrm{Ca}$. This may expand the repertoire of vegetables that can be eaten to achieve adequate $\mathrm{Ca}$ consumption.

Biofortification and nutritional studies. Many of the most popular vegetables are low in $\mathrm{Ca}$; therefore, biofortification of these popular vegetables, including potatoes and iceberg lettuce, provides a good target to increase $\mathrm{Ca}$ consumption. On average, Americans consume only 3.3 servings of vegetables a day (<http://www.fruitandveggiesmatter.gov $>$, $<$ http:apps.nccd.cdc.gov/5ADaySurveillance/>). Currently, less than $25 \%$ of the U.S. population reaches the adequate daily consumption of five daily portions of fruits and vegetables. These statistics argue for the development of strategies to increase the levels of healthpromoting compounds such as $\mathrm{Ca}$ in the vegetables that people consume in substantial amounts. The dark green vegetables (broccoli, bok choy, collard greens, kale, etc.), which may be high in dietary $\mathrm{Ca}$, represent only 0.2 of these daily servings. The number one vegetable eaten by Americans is potatoes followed by iceberg lettuce. In terms of $\mathrm{Ca}$ content, these vegetables are not as desirable as some of the dark leafy greens. Rather than trying to alter consumer preferences, our work here will enhance the $\mathrm{Ca}$ content of vegetables that are already popular among consumers. 
Potatoes: Traditionally potatoes have been grown and consumed in Europe and North America (<http://www.npcspud.com/ $>$ ). Recently, there has been a dramatic increase in potato production and demand in Asia, Africa. and Latin America. In fact, Asia now consumes almost half of the world's potato supply, but its huge population means that consumption per person is $\approx 25 \mathrm{~kg}$. The heartiest potato eaters remain Europeans $(85 \mathrm{~kg})$ and North Americans $(60 \mathrm{~kg})$. Percapita consumption is lowest, but increasing, in Africa and Latin America.

Potatoes are eaten all over the world in an assortment of different dishes. Potatoes are high in carbohydrate content (19\%), mostly in the form of starch, which provides energy, but the potato also provides a fair amount of protein $(2 \%)$. In addition, a medium-sized potato can provide $\approx 33 \%$ of the recommended daily allowance (RDA) of vitamin C, $\approx 20 \%$ of the RDA of vitamin $\mathrm{B} 6$, and $\approx 30 \%$ of the RDA of iron, as well as small amounts of thiamin, riboflavin, folate, niacin, magnesium, phosphorus, and zinc. An average-sized baked potato (including skin) contains only a small fraction $(3 \%)$ of the RDA for calcium.

Carrots: Carrots are one of the most popular vegetables in the United States (Simon and Goldman, 2007). Although consumption varies by ethnicity, age, and income, the average American eats 11 pounds of carrots per year. Carrots can be eaten in a variety of ways and raw carrots have become a popular ready-to-eat snack food. Since the 1980 s, baby carrots (carrots that have been peeled and cut into uniform cylinders) have transformed the way people eat carrots. Carrots are an excellent source of vitamin A, vitamin $\mathrm{C}$, vitamin $\mathrm{K}$, dietary fiber, and potassium. Calcium content in carrots is $\approx 30 \mathrm{mg} / \mathrm{cup}$ ( $3 \%$ of RDA).

Lettuce: Lettuce is an attractive dietary option for enhancing consumption of dietary $\mathrm{Ca}$. Like carrots, lettuce can be eaten raw (<http://www.foodreference.com/html/ artlettuce.html $>$ ). Per-capita consumption of all lettuce varieties has been increasing since 1960 and in 2004, annual lettuce consumption reached a record high of 34.5 pounds per capita. Some lettuces (especially iceberg) have been specifically bred to remove the bitterness from their leaves. These lettuces have high water content with very little nutrient value. However, lettuce is rich in vitamin $\mathrm{K}$ (as much as $167 \mu \mathrm{g} /$ head) but low in $\mathrm{Ca}(10 \mathrm{mg} / 1$ cup shredded, for $1 \%$ of RDA).

Modified potatoes, carrots, and lettuce will be used to translate our knowledge from model systems to crops that can benefit consumers. Alternative vegetables we have considered (after discussions with dieticians) include tomatoes and corn; however, these plants have proven recalcitrant to the approaches used in our studies (Park et al., 2005). Also, the difficulty in transforming many crops such as spinach makes these plants recalcitrant to our experimental approaches.
Preliminary studies suggest Ca biofortification efforts using potatoes, carrots, and lettuce should concentrate on fertilizer application and genetic engineering approaches. There is limited genetic variation among potatoes, carrot, and lettuce varieties in terms of $\mathrm{Ca}$ content, but these plants can be easily transformed to facilitate genetic engineering approaches. Additionally, we have working relationships in place with carrot and potatoes breeders at Texas A\&M (Park et al., 2004). These advantages have allowed us to design and implement an experimental pipeline to genetically alter these crops and measure nutrient bioavailability (Morris et al., 2008).

Biofortification: Increasing calcium transport activity. Calcium is transported from the soil into the edible portions of plants; increasing this transport may increase $\mathrm{Ca}$ content of vegetables (Conn et al., 2012; Dayod et al., 2010; Gilliham et al., 2011; Hirschi, 2009). Specifically, one approach is to manipulate plant endomembrane transporters to increase $\mathrm{Ca}$ transport. In animal cells and in yeast, capactitative $\mathrm{Ca}$ entry mechanisms are activated when vacuolar $\mathrm{Ca}$ transporters are highly expressed (Hirschi, 2001). In plants, Ca transport is highly regulated, but expression of a gene from a different plant species may bypass some of the endogenous regulatory mechanisms to produce higher activity of a given gene product (Diener and Hirschi, 2000). With this in mind, we expressed an Arabidopsis $\mathrm{Ca}$ transporter (CAX) in lettuce, carrots, and potatoes to increase $\mathrm{Ca}$. The potatoes, carrots, and lettuce showed on average a 2-fold increase in $\mathrm{Ca}$ content caused by expression of a single copy of the CAX cassette. In each case these changes were significant, stable, and heritable. In carrots, we used genetic crosses to a variety of different varieties to verify that this is a heritable trait. Using both biochemical analysis and microscopy, we noted no alteration in levels of oxalate, a potential antinutrient. In each case, these modifications did not appear to perturb growth, development, or fertility under controlled laboratory conditions (Park et al., 2004). Therefore, this transgenic approach provides a promising step toward increasing $\mathrm{Ca}$ contents in popular vegetables that are low in $\mathrm{Ca}$.

Sensory analysis of biofortified foods. Foods with improved nutrition will be useless if consumers refuse to eat them. Biofortification attempts have enhanced the nutritional quality of numerous foods (Diaz de la Garza et al., 2007), but few studies have assessed how genetically engineered foods alter the taste and consumer perception of foods (Park et al., 2009). Everyone has a different response to certain tastes and flavors but also to the texture and mouth-feel of foods. Sensory analysis applies principles of experimental design and statistical analysis to the use of human senses to evaluate a product. This requires panels of human assessors for product testing. By applying sensory analysis to genetically modified foods, we can begin to determine if these products are commercially viable. Another aspect of acceptance of new cultivars is the cultural element, particularly in non-Western countries.

Recently, biofortified lettuce was analyzed for taste and flavor compared with nontransgenic controls. Professional descriptive panelists determined attributes related to flavor, bitterness, and crispness of control and the sCAX1-expressing biofortified lettuce. The flavor of the biofortified lettuce was virtually identical to the controls and no effect was noted on bitterness and crispness. These studies suggest that consumer acceptance of the sCAX1-expressing lettuce should not be affected by effects on flavor, bitterness, or crispness.

Obviously another important issue is culturally acceptance, particularly in non-Western countries, but this will require a different set of tools to address.

\section{IMPACT OF THIS RESEARCH}

Historically, nutritional problems have centered on the inadequate intake of certain vitamins and minerals resulting in nutritional deficiencies (Frazao, 1999). Currently, nutritional problems in America are driven by the strong link between nutrition and chronic diseases. A majority of Americans are interested in improving their diets and many are changing their diets by attempting to move closer to established dietary recommendations (Hornick et al., 2008). However, the direction and magnitude of these changes vary considerably, both among individuals and among food groups. For example, survey data suggest a trend toward lower fat diets. However, the same data show that individuals are not increasing their consumption of fruits and vegetables as recommended and that the prevalence of obesity is rising (CDC, 2008; Wareham et al., 2005).

Government assistance can also influence consumer dietary choices (Ralston et al., 2008). Food assistance programs can affect the amount and the types of foods eaten by low-income consumers. However, the longterm changes on the consumer diet, especially after leaving the program, have so far been unclear. Certainly, greater food expenditure does not necessarily imply a more healthful diet. For the more narrowly targeted programs such as the School Lunch Program, nutrient intake typically increases (at least while the recipient remains in the program). For example, children in schools with restricted snack availability had significantly higher frequency of fruit and vegetable consumption than children in schools without restricted snack availability. These findings suggest that a restrictive snack policy should be part of a multifaceted approach to improve children's diet (Gonzalez et al., 2009).

We are seeking to provide substantial benefit to the consumer at no inconvenience and minimal cost. This passive method does not require consumer knowledge, understanding, or commitment to change food consumption behavior. Increasing the dietary $\mathrm{Ca}$ levels 5 -fold in potatoes, lettuce, and carrots could have a significant effect on total $\mathrm{Ca}$ 
consumption in the United States without requiring alteration of dietary habits. Currently, Americans receive less than 2\% of their recommended daily intake (RDI) of $\mathrm{Ca}$ from these vegetables (RDI of $1100 \mathrm{mg}$ Ca per day). The U.S. RDI for $\mathrm{Ca}$ is linked to a person's age and stage of life, so among adolescents, these vegetables contribute even less to their daily $\mathrm{Ca}$ requirements. If Americans continue to eat $60 \mathrm{~kg}$ of potatoes a year ( $\approx 150$ medium-sized potatoes), they would receive a net benefit of $18,000 \mathrm{mg}$ of $\mathrm{Ca}$ from these alterations $(22,500$ in the biofortified potatoes vs. 4,500 in the varieties found today). For lettuce, if Americans continue to eat $35 \mathrm{lbs}$ of lettuce per year $(\approx 200$ servings of 1 shredded cup), the net gain in $\mathrm{Ca}$ would be $8,000 \mathrm{mg}$ from this food $(10,000 \mathrm{mg}$ in the biofortified vs. 2,000 in the standard variety). For carrots, if Americans consume 11 pounds of carrots per year (35 servings of chopped carrots), that would increase $\mathrm{Ca}$ consumption by $4100 \mathrm{mg}(5250 \mathrm{mg}$ from the biofortified carrots compared with the $1050 \mathrm{mg}$ from standard carrots). These back-of-theenvelope calculations and predictions assume optimal preparation of the vegetables to ensure $\mathrm{Ca}$ bioavailability. Bearing in mind these caveats, these $\mathrm{Ca}$ biofortified vegetables could contribute $\approx 5 \%$ of the RDI of $\mathrm{Ca}$ for a wide array of Americans.

\section{GENETICALLY MODIFIED FOODS: "FARMERS AND CONSUMERS"}

The possibilities associated with transgenic approaches keep plant biologists and production agriculture scientists optimistic despite the current political and economic landscape, which is not completely receptive to this technology (Freese and Schubert, 2004; ISLI, 2008; Johnson et al., 2007; Powell, 2007; Weil, 2005). Even with these current limitations, the potential for genetic modifications to alleviate hunger and nutrient deficiencies warrants advocacy of this technology by scientists and citizens.

The integration of genetically modified foods into modern agriculture and our current food supply can be exemplified by the work of the St. Louis-based biotechnology company Monsanto (Hindo, 2007). The majority of Monsanto crops is not directly consumed by humans, but rather for people to ingest them indirectly. For example, the majority of Monsanto's genetically modified corn is used to make animal feed and ethanol but a portion goes into the food supply as corn syrup and cornstarch as well as to make some tortilla chips. Also, the bulk of biotech cotton feeds the textile industry. However, cotton byproducts do end up in the food chain as cottonseed oil, which can be used to make mayonnaise and margarine. Another illuminating example is papaya. An estimated $80 \%$ of the papayas from Hawaii are genetically engineered. This technology is publically licensed and sold to farmers through a not-for-profit group. Although these are just a few examples, in the United States, $\approx 60 \%$ of all "formulated foods"-processed food with more than one ingredient that contains genetically modified organisms (GMOs).

The work outlined here may also promote positive viewpoints among consumers regarding genetically modified foods. Our previous studies addressing the bioavailability of $\mathrm{Ca}$ using the CAX-expressing carrots was well received by the media, including news articles by the BBC and NPR (press articles can be found at $<$ http://www.bcm.edu/cnrc/ faculty/kendalh.htm $>$ ). An article in the London Telegraph (<http://www.telegraph. co.uk/scienceandtechnology/science/science news/3321694/GM-carrot-may-help-treatosteoporosis.html $>$ ) talking about our work contained the subheading: "Europe will be forced to re-think on GM crops." We believe our studies are part of the foundation that will make healthier genetically modified foods an established ingredient in the diets of future generations.

Vegetable crops provide some of the highest concentrations of vitamins and minerals in the human diet. Many modern cultivars have been selected through intensive breeding programs for enhanced yield and disease resistance. Major quality traits such as sugars and color have also been improved for aesthetic or flavor-related attributes. These traits may also lead to enhanced levels of beneficial bioactives such as ascorbic acid and carotenoids, which in some vegetables are correlated with intensity of color and sugar levels. Carrots, sweetpotatoes, tomatoes, melons, and winter squash are good examples of vegetables with carotenoids levels that have been genetically enhanced through breeding and selection. However, there are many fruit and vegetable crops and cultivars that have the potential to have higher levels of health-related compounds such as vitamins, flavonoids, and amino acids. Often some wild species, unimproved germplasm, or breeding lines may possess higher concentrations of these beneficial bioactives but lack other key commercial traits. Therefore, the integration of plant breeding and health sciences needs to be emphasized in future research programs.

\section{Literature Cited}

Abrams, S.A. and G.J. Strewler. 2007. Adolescence: How do we increase intestinal calcium absorption to allow for bone mineral mass accumulation? International Bone \& Mineral Society 4:147-157.

Adams, C.F. and M. Richardson. 1981. Nutritive value of foods. Book nutritive value of foods. US Department of Agriculture, Science and Education Administration.

Afari-Sefa, V. and A. Tenkouano. et al. 2012 Vegetable breeding in Africa: Constraints, complexity and contributions toward achieving food and nutritional security. Food Security $4: 115-127$.

Ajjawi, I. and D. Shintani. 2004. Engineered plants with elevated vitamin E: A nutraceutical success story. Trends Biotechnol. 22:104-107.

Amiot, M. 2008. Fruit, vegetables, phytochemicals and human health: Past and future. I International Symposium on Horticulture in Europe 817:61-70.

Apel, W. and R. Bock. 2009. Enhancement of carotenoid biosynthesis in transplastomic tomatoes by induced lycopene-to-provitamin A conversion. Plant Physiol. 151:59-66.

Atkinson, S.A., G.P. McCabe, C.M. Weaver, S.A Abrams, and K.O. O'Brien. 2008. Are current calcium recommendations for adolescents higher than needed to achieve optimal peak bone mass? The controversy. J. Nutr. 138:1182-1186.

Bachrach, L. K. 1999. Malnutrition, endocrinopathies, and deficits in bone mass acquisition, p. 261-277. In: Bonjour, J.-P. and Tsang, R. C. (eds.), Nutrition and Bone Development. Vevey/Lippincott-Raven Publishers, Philadelphia, PA.

Bachrach, L.K. 2001. Acquisition of optimal bone mass in childhood and adolescence. Trends Endocrinol. Metab. 12:22-28.

Bailey, D.G. and J. Malcolm. et al. 1998. Grapefruit juice-drug interactions. Brit. J. Clin. Pharmacol. 46:101-110.

Baranski, R., C. Allender, and M. Klimek-Chodacka. 2012. Towards better tasting and more nutritious carrots: Carotenoid and sugar content variation in carrot genetic resources. Food Res. Intl. 47:182-187.

Beddington, J. 2011. The future of food and farming: Challenges and choices for global sustainability. Government Office for Science, London, UK.

Bekaert, S., S. Storozhenko, P. Mehrshahi, M.J. Bennett, W. Lambert, J.F. Gregory, K. Schubert, J. Hugenholtz, D. Van Der Straeten, and A.D. Hanson. 2008. Folate biofortification in food plants. Trends Plant Sci. 13:28-35.

Bharti, S.K. and R. Roy. 2012. Quantitative 1H NMR spectroscopy. TrAC Trends in Analytical Chemistry 35:5-26.

Brigelius-Flohe, R. and H.-G. Joost. 2006. Nutritional genomics: Impact on health and disease, p. 3-17. In: Book nutritional genomics: Impact on health and disease. Wiley-VCH Verlag $\mathrm{GmBH} \&$ Company KGaA, Weinheim, Germany.

Brodbelt, J.S., J.M. Zhang, M. Pikulski, B.A Davis, B. Girennavar, G.K. Jayaprakasha, and B.S. Patil. 2006. of Conference. Characterization of flavonoids by tandem mass spectrometry and metal complexation strategies, Conference Location Date (ACS Symposium Series 936).

Bruinsma, J. 2009. The resource outlook to 2050: By how much do land, water and crop yields need to increase by 2050 ? p. 1-33.

Butalla, A.C., T.E. Crane, B.S. Patil, B.C. Wertheim, P. Thompson, and C.A. Thomson. 2012. Effects of a carrot juice intervention on plasma carotenoids, oxidative stress, and inflammation in overweight breast cancer survivors. Nutr. Cancer 64:331-341.

Butcher, J.D., K.M. Crosby, K.S. Yoo, B.S. Patil, A. Ibrahim, D.I. Leskovar, and J.L. Jifon. 2012. Environmental and genotypic variation of capsaicinoid and flavonoid concentrations in habanero (Capsicum chinense) peppers. HortScience 47:574-579.

Butcher, J.D., K.M. Crosby, K.S. Yoo, B.S. Patil, J.L. Jifon, and W.L. Rooney. 2013. Heterosis in different F1 Capsicum annuum genotypes for fruit traits, ascorbic acid, capsaicin, and flavonoids. Sci. Hort. 159:72-79.

Byrne, D.H., G. Noratto, L. Cisneros Zevallos, W. Porter, and M. Vizzotto. 2009. Health benefits of peaches and plums. Acta Hort. 841:267-274.

Byrne, D.H. 2012. Trends in fruit breeding, p 3-36. Handbook of plant breeding: Fruit breeding. In: M. Badenes and D. H. Byrne (eds.). Springer, NewYork.

Cantiin, C.M., M.A. Moreno, and Y. Gogorcena. 2009. Evaluation of the antioxidant capacity, phenolic compounds, and vitamin $\mathrm{C}$ content of 
different peach and nectarine [Prunus persica (L.) Batsch] breeding progenies. J. Agr. Food Chem. 57:4586-4592.

Carroccio, A., G. Montalto, G. Cavera, and A. Notarbatolo. 1998. Lactose intolerance and self-reported milk intolerance: Relationship with lactose maldigestion and nutrient intake. Lactase Deficiency Study Group. J. Amer. Coll. Nutr. 17:631-636.

CDC. 2008. State-specific prevalence of obesity among adults-United States, 2007, p. 765-768. In: U. S. C. f. D. C. a. P. (CDC) (ed.). Morbidity and Mortality Weekly Report (MMWR), Atlanta, GA

Cevallos-Casals, B.A., D. Byrne, W.R. Okie, and L. Cisneros-Zevallos. 2006. Selecting new peach and plum genotypes rich in phenolic compounds and enhanced functional properties. Food Chem. 96:273-280.

Chang, S., C. Tan, E.N. Frankel, and D.M. Barrett. 2000. Low-density lipoprotein antioxidant activity of phenolic compounds and polyphenol oxidase activity in selected clingstone peach cultivars. J. Agr. Food Chem. 48:147-151.

Chebrolu, K.K., G.K. Jayaprakasha, J. Jifon, and B.S. Patil. 2011. Optimization of flavanones extraction by modulating differential solvent densities and centrifuge temperatures. Talanta 85:353-362.

Chen, C., P. Cancalon, C. Haun, and F. Gmitter. 2011. Characterization of furanocoumarin profile and inheritance toward selection of low furanocoumarin seedless grapefruit cultivars. J. Amer. Soc. Hort. Sci. 136:358-363.

Chidambara Murthy, K.N., J. Kim, A. Vikram, and B.S. Patil. 2012. Differential inhibition of human colon cancer cells by structurally similar flavonoids of citrus. Food Chem. 132:2734.

Chong, M.F.F., R. Macdonald, and J.A. Lovegrove. 2010. Fruit polyphenols and CVD risk: A review of human intervention studies. Brit. J. Nutr. 104:S28-S39.

Christou, P. and R.M. Twyman. 2004. The potential of genetically enhanced plants to address food insecurity. Nutr. Res. Rev. 17:23-42.

Colson, G. and W.E. Huffman. 2011. Consumers' willingness to pay for genetically modified foods with product-enhancing nutritional attributes. Amer. J. Agr. Econ. 93:358-363.

Conforti, F., G.A. Statti, and F. Menichini. 2007. Chemical and biological variability of hot pepper fruits (Capsicum annuum var. acuminatum L.) in relation to maturity stage. Food Chem. 102:1096-1104.

Conn, S.J., P. Berninger, M.R. Broadley, and M. Gilliham. 2012. Exploiting natural variation to uncover candidate genes that control element accumulation in Arabidopsis thaliana. New Phytol. 193:859-866.

Connor, A.M., C.E. Finn, and P.A. Alspach. 2005a. Genotypic and environmental variation in antioxidant activity and total phenolic content among blackberry and hybrid berry cultivars. J. Amer. Soc. Hort. Sci. 130:527-533.

Connor, A.M., T.K. McGhie, M.J. Stephens, H.K. Hall, and P.A. Alspach. 2005b. Variation and heritability estimates of anthocyanins and their relationship to antioxidant activity in a red raspberry factorial mating design. J. Amer. Soc. Hort. Sci. 130:534-542.

Connor, A.M., M.J. Stephens, H.K. Hall, and P.A. Alspach. 2005c. Variation and heritabilities of antioxidant activity and total phenolic content estimated from a red raspberry factorial experiment. J. Amer. Soc. Hort. Sci. 130:403-411.

Connor, A.M., J.J. Luby, and C.B. Tong. 2002a. Variation and heritability estimates for antioxidant activity, total phenolic content, and anthocyanin content in blueberry progenies. J. Amer. Soc. Hort. Sci. 127:82-88.

Connor, A.M., J.J. Luby, and C.B. Tong. 2002 b. Genotypic and environmental variation in antioxidant activity, total phenolic content, and anthocyanin content among blueberry cultivars. J. Amer. Soc. Hort. Sci. 127:89-97.

Corcoran, O. and M. Spraul. 2003. LC-NMR-MS in drug discovery. Drug Discov. Today 8:624-631.

Crosby, K., G. Lester, and D. Leskovar. 2006. Genetic variation for beneficial phytochemical levels in melons (Cucumis melo L.).

Crosby, K.M., J.L. Jifon, B. Villalon, and D.I Leskovar. 2007. 'TAM Dulcito', a new, multiple virus-resistant sweet jalapeño pepper. HortScience 42:1488-1489.

Crosby, K.M., D.I. Leskovar, and K.S. Yoo. 2005a (253) TAM 'Dulcito' and 'Tropic Bell'-Two new sweet peppers with enhanced beneficial phytochemical levels. HortScience 40:1020.

Crosby, K.M., D.I. Leskovar, and K.S. Yoo. 2005 b. 'TAM Mild Habanero', a low-pungency habanero pepper. HortScience 40:490-491.

Danaei, G., S. Vander Hoorn, A.D. Lopez, C.J Murray, and M. Ezzati. 2005. Causes of cancer in the world: Comparative risk assessment of nine behavioural and environmental risk factors. Lancet 366:1784-1793.

Darnton-Hill, I. and R. Nalubola. 2002. Fortification strategies to meet micronutrient needs: Successes and failures. Proc. Nutr. Soc. 61:231241.

Davuluri, G.R., A. Van Tuinen, P.D. Fraser, A. Manfredonia, R. Newman, D. Burgess, D.A Brummell, S.R. King, J. Palys, and J. Uhlig. 2005. Fruit-specific RNAi-mediated suppression of DET1 enhances carotenoid and flavonoid content in tomatoes. Nat. Biotechnol. 23:890-895

Dawson-Hughes, B. 2006. Calcium plus vitamin D and the risk of fractures. N. Engl. J. Med 354:2285-2287; author reply 2285-2287.

Dayod, M., S.D. Tyerman, R.A. Leigh, and M. Gilliham. 2010. Calcium storage in plants and the implications for calcium biofortification. Protoplasma 247:215-231.

DellaPenna, D. 1999. Nutritional genomics: Manipulating plant micronutrients to improve human health. Science 285:375-379.

DellaPenna, D. 2007. Biofortification of plantbased food: Enhancing folate levels by metabolic engineering. Proc. Natl. Acad. Sci. USA 104:3675-3676.

Diaz de la Garza, R.I., J.F. Gregory, III, and A.D. Hanson. 2007. Folate biofortification of tomato fruit. Proc. Natl. Acad. Sci. USA 104:42184222.

Diener, A. and H. Hirschi. 2000. Heterologous expression for dominant-like gene activity. Trends Plant Sci. 5:10-11.

Dillard, C.J. and J.B. German. 2000. Phytochemicals: Nutraceuticals and human health. J. Sci. Food Agr. 80:1744-1756.

Diretto, G., R. Tavazza, R. Welsch, D. Pizzichini, F. Mourgues, V. Papacchioli, P. Beyer, and G. Giuliano. 2006. Metabolic engineering of potato tuber carotenoids through tuber-specific silencing of lycopene epsilon cyclase. BMC Plant Biol. 6:13.

El-Houri, R.B., D.E. Kotowska, K.B. Christensen, X. Fretté, K. Kristiansen, and L.P. Christensen. 2012. Polyacetylenes from carrots with potential anti-diabetic effects. Planta Med. 78:PI349.

FAO. 1996. Declaration on world food security. World food summit. FAO, Rome, Italy.

Faulkner, K., R. Mithen, and G. Williamson. 1998. Selective increase of the potential anticarcinogen 4-methylsulphinylbutyl glucosinolate in broccoli. Carcinogenesis 19:605-609.

Finley, J.W. 2005. Bioactive compounds and designer plant foods: The need for clear guidelines to evaluate potential benefits to human health. Chronica Horticulturae 45:6-11.

Frazao, E. 1999. America's Eating Habits: Changes and consequences, p. 484. In: T. E. o. F. U.S. Department of Agriculture Economic Research Service, Farming, Natural Resources, and Rural America (eds.). U.S. Department of Agriculture Economic Research Service, Washington, DC.

Freese, W. and D. Schubert. 2004. Safety testing and regulation of genetically engineered foods. Biotechnol. Genet. Eng. Rev. 21:299-324.

Geleta, L.F. and M.T. Labuschagne. 2006. Combining ability and heritability for vitamin $\mathrm{C}$ and total soluble solids in pepper (Capsicum annuum L.). J. Sci. Food Agr. 86:1317-1320.

Gilligan, D.O. 2012. Biofortification, agricultural technology adoption, and nutrition policy: Some lessons and emerging challenges. CESifo Economic Studies 58:405-421.

Gilliham, M., M. Dayod, B.J. Hocking, B. Xu, S.J. Conn, B.N. Kaiser, R.A. Leigh, and S.D. Tyerman. 2011. Calcium delivery and storage in plant leaves: Exploring the link with water flow. J. Expt. Bot. 62:2233-2250.

Girennavar, B., G.K. Jayaprakasha, Y. Jadegoud, G.A. Nagana Gowda, and B.S. Patil. 2007. Radical scavenging and cytochrome P450 3A4 inhibitory activity of bergaptol and geranylcoumarin from grapefruit. Bioorg. Med. Chem. 15:3684-3691.

Gonzalez, W., S.J. Jones, and E.A. Frongillo. 2009. Restricting snacks in U.S. elementary schools is associated with higher frequency of fruit and vegetable consumption. J. Nutr. 139:142-144.

Greer, F.R. and N.F. Krebs. 2006. Optimizing bone health and calcium intakes of infants, children, and adolescents. Pediatrics 117:578-585.

Haponik, C., A. Reboucas, W.D. Paiva, A.d.S. Almeida, J. Mosca, E.d.O. Silva, and R. Alves. 2004. Selection of progeny of 'Tupa' melon for quality and nutritional value. 47

Hemavathi, C. Upadhyaya, N. Akula, K. Young, S. Chun, D. Kim, and S. Park. 2010. Enhanced ascorbic acid accumulation in transgenic potato confers tolerance to various abiotic stresses. Biotechnol. Lett. 32:321-330.

Hindo, B. 2007. Monsanto: Winning the ground war. BusinessWeek.

Hirschi, K. 2001. Vacuolar $\mathrm{H}^{+} / \mathrm{Ca}^{2+}$ transport: Who's directing the traffic? Trends Plant Sci. 6:100-104.

Hirschi, K.D. 2009. Nutrient biofortification of food crops. Annu. Rev. Nutr. 29:401-421.

Hornick, B.A., A.J. Krester, and T.A. Nicklas. 2008. Menu modeling with MyPyramid food patterns: Incremental dietary changes lead to dramatic improvements in diet quality of menus. J. Amer. Diet. Assoc. 108:2077-2083.

Howard, L., S. Talcott, C. Brenes, and B. Villalon. 2000. Changes in phytochemical and antioxidant activity of selected pepper cultivars ( Capsicum species) as influenced by maturity. J. Agr. Food Chem. 48:1713-1720.

Huncharek, M., J. Muscat, and B. Kupelnick. 2008. Impact of dairy products and dietary calcium on bone-mineral content in children: Results of a meta-analysis. Bone 43:312-321.

ISLI. 2008. Nutritional and safety assessments of foods and feeds nutritionally improved through biotechnology: Case studies. Comprehensive Reviews in Food Science and Food Safety. International Life Sciences Institute 7:50-99.

Jachertz, R. 2012. of Conference. United Nations Food and Agriculture Organization, Conference Location Date. 
Jayaprakasha, G.K., K.N. Chidambara Murthy, and B.S. Patil. 2011a. Rapid HPLC-UV method for quantification of L-citrulline in watermelon and its potential role on smooth muscle relaxation markers. Food Chem. 127:240-248.

Jayaprakasha, G.K., D.V. Dandekar, S.E. Tichy, and B.S. Patil. 2011b. Simultaneous separation and identification of limonoids from citrus using liquid chromatography collision induced dissociation mass spectra. J. Sep. Sci. 34:2-10.

Jayaprakasha, G.K., Y. Jadegoud, G.A. Nagana Gowda, and B.S. Patil. 2009. Bioactive compounds from sour orange inhibit colon cancer cell proliferation and induce cell cycle arrest. J. Agr. Food Chem. 58:180-186.

Jayaprakasha, G.K., B.S. Jena, and K.K. Sakariah. 2003. An improved HPLC method for the determination of organic acids in leaves, pulp, fruits and rinds of Garcinia. J. AOAC Intl. 86:1003-1007.

Jayaprakasha, G.K., K.K. Mandadi, S.M. Poulose, Y. Jadegoud, G.A. Nagana Gowda, and B.S. Patil. 2007. Inhibition of colon cancer cell growth and antioxidant activity of bioactive compounds from Poncirus trifoliata (L.) Raf. Bioorg. Med. Chem. 15:4923-4932.

Jayaprakasha, G.K., K.K. Mandadi, S.M. Poulose, Y. Jadegoud, G.A. Nagana Gowda, and B.S. Patil. 2008. Novel triterpenoid from Citrus aurantium L. possesses chemopreventive properties against human colon cancer cells. Bioorg. Med. Chem. 16:5939-5951.

Jayaprakasha, G.K., K.N.C. Murthy, and B.S. Patil. 2012a. Inhibition of pancreatic cancer cells by furocoumarins from Poncirus trifoliata. Planta Med. 78:PI175.

Jayaprakasha, G.K., K. Chidambara Murthy, M. Etlinger, S.M. Mantur, and B.S. Patil. 2012b. Radical scavenging capacities and inhibition of human prostate $(\mathrm{LNCaP})$ cell proliferation by Fortunella margarita. Food Chem. 131:184191.

Jayaprakasha, G.K., K. Murthy, R.M. Uckoo, and B.S. Patil. 2013. Chemical composition of volatile oil from Citrus limettioides and their inhibition of colon cancer cell proliferation. Ind. Crops Prod. 45:200-207.

Jayaprakasha, G.K. and B.S. Patil. 2010. Extraction efficiency of carotenoids and their antioxidant activity. In: 239th ACS National Meeting. San Francisco meeting, San Francisco, CA.

Jeffery, E.H., A.F. Brown, A.C. Kurilich, A.S Keck, N. Matusheski, B.P. Klein, and J.A. Juvik. 2003. Variation in content of bioactive components in broccoli. J. Food Compost. Anal. 16:323-330.

Johnson, K.L., A.F. Raybould, M.D. Hudson, and G.M. Poppy. 2007. How does scientific risk assessment of GM crops fit within the wider risk analysis? Trends Plant Sci. 12:1-5.

Just, B.J. and P.W. Simon, 2004. Mapping of Major Carrot Color Genes an Expression of Carotenoid Biosynthetic Genes. HortScience 39:870-870.

Kappel, F. 2005. Breeding cherries in the. New World.

Kaul, S., S. Gupta, M. Ahmed, and M.K. Dhar. 2012. Endophytic fungi from medicinal plants: A treasure hunt for bioactive metabolites. Phytochem. Rev. 1-19.

Khanizadeh, S., R. Tsao, D. Rekika, R. Yang, M. Charles, and H. Rupasinghe. 2007. Advances in fruit breeding in eastern Canada-Role of phytochemicals in designing specialty fruits.

Kim, J., G.K. Jayaprakasha, M. Muthuchamy, and B.S. Patil. 2011. Structure-function relationships of citrus limonoids on p38 MAP kinase activity in human aortic smooth muscle cells. Eur. J. Pharmacol. 670:44-49.
Kim, J.H., G.K. Jayaprakasha, A. Vikram, and B.S. Patil. 2012. Cancer Chemopreventive Properties of Citrus Limonoids, p. 37-50, Emerging Trends in Dietary Components for Preventing and Combating Disease. American Chemical Society.

Lanou, A.J. 2006. Bone health in children. BMJ 333:763-764.

Lanou, A.J., S.E. Berkow, and N.D. Barnard. 2005. Calcium, dairy products, and bone health in children and young adults: A reevaluation of the evidence. Pediatrics 115:736-743.

Lata, B. 2007. Relationship between apple peel and the whole fruit antioxidant content: Year and cultivar variation. J. Agr. Food Chem. 55:663-671.

Lata, B., M. Przeradzka, and M. Binkowska. 2005 Great differences in antioxidant properties exist between 56 apple cultivars and vegetation seasons. J. Agr. Food Chem. 53:8970-8978.

Łata, B., A. Trampczynska, and J. Paczesna. 2009 Cultivar variation in apple peel and whole fruit phenolic composition. Sci. Hort. 121:176-181.

Lazcano, C. 1999. 'BetaSweet' carrot: Production, flavor, nutritional attributes and market strategies. $\mathrm{PhD}$ diss., Texas A\&M University, College Station, TX.

Lee, J.J., K.M. Crosby, L.M. Pike, K.S. Yoo, and D.I. Leskovar. 2005. Impact of genetic and environmental variation on development of flavonoids and carotenoids in pepper (Capsicum spp.). Sci. Hort. 106:341-352.

Lee, E., K. Yoo, and B.S. Patil. 2011. Total carotenoid, anthocyanin, and sugar contents in sliced or whole purple (cv. Betasweet) and orange carrots during 4-week cold storage. Horticulture, Environment, and Biotechnology 52:402-407.

Leong, S.Y. and I. Oey. 2012. Effects of processing on anthocyanins, carotenoids and vitamin $\mathrm{C}$ in summer fruits and vegetables. Food Chem. 133:1577-1587.

Lester, G. 1997. Melon (Cucumis melo L.) fruit nutritional quality and health functionality. HortTechnology 7:222-227.

Lester, G. and B. Bruton. 1986. Relationship of netted muskmelon fruit water loss to postharvest storage life. J. Amer. Soc. Hort. Sci. 111:727731.

Lester, G. and F. Eischen. 1996. Beta-carotene content of postharvest orange-fleshed muskmelon fruit: Effect of cultivar, growing location and fruit size. Plant Foods Hum. Nutr. 49:191-197.

Lester, G. and R. Turley. 1990. Chemical, physical and sensory comparisons of netted muskmelon fruit cultivars and breeding lines at harvestJournal of the Rio Grande Valley Horticultural Society 43.

Lester, G.E. and K.M. Crosby. 2002. Ascorbic acid, folic acid, and potassium content in postharvest green-flesh honeydew muskmelons: Influence of cultivar, fruit size, soil type, and year. J. Amer. Soc. Hort. Sci. 127:843-847.

Lewinsohn, E., F. Schalechet, J. Wilkinson, K. Matsui, Y. Tadmor, K.-H. Nam, O. Amar, E. Lastochkin, O. Larkov, and U. Ravid. 2001. Enhanced levels of the aroma and flavor compound S-linalool by metabolic engineering of the terpenoid pathway in tomato fruits. Plant Physiol. 127:1256-1265.

Li, X., J. Yang, J. Morris, A. Hester, and P. Nakata. Genetically modified Medicago truncatula lacking calcium oxalate has increased calcium bioavailability and partially rescues vitamin D receptor knockout mice phenotypes. J Bioequiv Availab. 5:047-052.

Liu, J., C. Folberth, H. Yang, J. Röckström, K. Abbaspour, and A.J.B. Zehnder. 2013. A global and spatially explicit assessment of climate change impacts on crop production and consumptive water use. PLoS One 8:e57750.

Liu, R.H. 2003. Health benefits of fruit and vegetables are from additive and synergistic combinations of phytochemicals. Amer. J. Clin. Nutr. 78:517S-520S

Liu, R.H. 2004. Potential synergy of phytochemicals in cancer prevention: Mechanism of action. J. Nutr. 134:3479S-3485S.

Liu, Z., J. Schwimer, D. Liu, F.L. Greenway, C.T. Anthony, and E.A. Woltering. 2005. Black raspberry extract and fractions contain angiogenesis inhibitors. J. Agr. Food Chem. 53:3909-3915.

Low, J., M. Arimond, N. Osman, A.K. Osei, F. Zano, B. Cunguara, M. Selemane, D. Abdullah, and D. Tschirley. 2005. Towards sustainable nutrition improvement in rural Mozambique: Addressing macro-and micro-nutrient malnutrition through new cultivars and new behaviors: Key findings. Book towards sustainable nutrition improvement in rural Mozambique: Addressing macro-and micro-nutrient malnutrition through new cultivars and new behaviors: Key findings. MSU.

Marinelli, J. and B.C. Hanson. 1999. Chile peppers: Hot tips and tasty picks for gardeners and gourmets, (Vol. 161). B. C. Hanson (Ed.). Brooklyn Botanic Garden.

Martin, B.R., S. Davis, W.W. Campbell, and C.M Weaver. 2007. Exercise and calcium supplementation: Effects on calcium homeostasis in sportswomen. Med. Sci. Sports Exerc. 39:1481-1486.

Martin-Belloso, O. and R.S. Fortuny. 2011. Advances in fresh-cut fruits and vegetables processing, p. VII In: Book advances in fresh-cut fruits and vegetables processing. (ed.) MartinBelloso, O. and R.S. Fortuny. CRC Press, Boca Raton, FL.

Matlik, L., D. Savaiano, G. McCabe, M. VanLoan, C.L. Blue, and C.J. Boushey. 2007. Perceived milk intolerance is related to bone mineral content in 10- to 13-year-old female adolescents. Pediatrics 120:e669-e677.

McDougall, G., P. Dobson, F. Shpiro, P. Smith, D. Stewart, and S. Fyffe. 2005. Assessing bioavailability of soft fruit polyphenols in vitro.

Merrilees, M.J., E.J. Smart, N.L. Gilchrist, C. Frampton, J.G. Turner, E. Hooke, R.L. March, and P. Maguire. 2000. Effects of diary food supplements on bone mineral density in teenage girls. Eur. J. Nutr. 39:256-262.

Mes, P.J., P. Boches, J.R. Myers, and R. Durst. 2008. Characterization of tomatoes expressing anthocyanin in the fruit. J. Amer. Soc. Hort. Sci. 133:262-269.

Meyers, K.J., C.B. Watkins, M.P. Pritts, and R.H. Liu. 2003. Antioxidant and antiproliferative activities of strawberries. J. Agr. Food Chem. 51:6887-6892.

Milde, J., E.F. Elstner, and J. Graßmann. 2007. Synergistic effects of phenolics and carotenoids on human low density lipoprotein oxidation. Mol. Nutr. Food Res. 51:956-961.

Morris, J., K.M. Hawthorne, T. Hotze, S.A. Abrams, and K.D. Hirschi. 2008. Nutritional impact of elevated calcium transport activity in carrots. Proc. Natl. Acad. Sci. USA 105:1431-1435.

Moyer, R.A., K.E. Hummer, C.E. Finn, B. Frei, and R.E. Wrolstad. 2002. Anthocyanins, phenolics, and antioxidant capacity in diverse small fruits: Vaccinium, Rubus, and Ribes. J. Agr. Food Chem. 50:519-525.

Muir, S.R., G.J. Collins, S. Robinson, S. Hughes, A. Bovy, C.R. De Vos, A.J. van Tunen, and 
M.E. Verhoeyen. 2001. Overexpression of petunia chalcone isomerase in tomato results in fruit containing increased levels of flavonols. Nat. Biotechnol. 19:470-474.

Murakami, A. and K. Ohnishi. 2012. Target molecules of food phytochemicals: Food science bound for the next dimension. Food \& Function 3:462-476.

Nestle, M. 2001. Genetically engineered 'golden' rice unlikely to overcome vitamin A deficiency. J. Amer. Diet. Assoc. 101:289-290.

Park, S., C.-K. Kim, L.M. Pike, R.H. Smith, and K.D. Hirschi. 2004. Increased calcium in carrots by expression of an Arabidopsis $\mathrm{H}^{+} / \mathrm{Ca}^{2+}$ transporter. Mol. Breed. 14:275-282.

Park, S., T.-S. Kang, C.-K. Kim, J.-S. Han, S. Kim, R.H. Smith, L.M. Pike, and K.D. Hirschi. 2005. Genetic manipulation for enhancing calcium content in potato tuber. Journal of Agricultural and Food Chemistry 53:5598-5603.

Park, S., M.P. Elless, J. Park, A. Jenkins, W. Lim, E. Chambers IV, and K.D. Hirschi. 2009. Sensory analysis of calcium-biofortified lettuce. Plant Biotechnol. J. 7:106-117.

Patil, B.S., G.K. Jayaprakasha, K.N. Chidambara Murthy, and A. Vikram. 2009. Bioactive compounds: Historical perspectives, opportunities, and challenges. J. Agr. Food Chem. 57:81428160.

Patil, B.S., G.K. Jayaprakasha, and A. Vikram. 2012. Indigenous crops of Asia and Southeast Asia: Exploring health-promoting properties. HortScience 47:821-827.

Perez, J.L., G. Jayaprakasha, V. Valdivia, D. Munoz, D.V. Dandekar, H. Ahmad, and B.S. Patil. 2009. Limonin methoxylation influences the induction of glutathione S-transferase and quinone reductase. J. Agr. Food Chem. 57:5279-5286.

Perez, J.L., G.K. Jayaprakasha, K.S. Yoo, and B.S. Patil. 2008. Development of a method for the quantification of d-glucaric acid in different varieties of grapefruits by high-performance liquid chromatography and mass spectra. J. Chromatography 1190:394-397.

Pollack, S. and A. Perez. 2008. Fruit and tree nuts situation and outlook yearbook 2008. US Department of Agriculture-Economic Research Service, Washington, DC.

Powell, K. 2007. Functional foods from biotechAn unappetizing prospect? Nat. Biotechnol. 25:525-531.

Prentice, A. 2004. Diet, nutrition and the prevention of osteoporosis. Public Health Nutr. 7: 227-243.

Prior, R.L., G. Cao, A. Martin, A., E. Sofic, J. McEwen, C. O'Brien, N. Lischner, M. Ehlenfeldt, W. Kalt, and G. Krewer. 1998. Antioxidant capacity as influenced by total phenolic and anthocyanin content, maturity, and variety of Vaccinium species. J. Agr. Food Chem. 46:26862693.

Program, N. S. o. t. W. F. 2006. Micronutrient fortification: WFP experiences and ways forward, p. 67-75. In: N. S. o. t. W. F. Program (ed.). The United National University Press, Boston, MA.

Ralston, K., C. Newman, A. Clauson, J. Guthrie, and J. Buzby. 2008. The national school lunch program background, trends, and issues, p. 56. In: T. E. o. F. U.S. Department of Agriculture Economics Research Service, Farming, Natural Resources, and Rural America (ed.). U.S. Department of Agriculture Economics Research Service, Washington, DC.

Raman, G., G.K. Jayaprakasha, J. Brodbelt, M. Cho, and B.S. Patil. 2004. Isolation of structurally similar citrus flavonoids by flash chromatography. Anal. Lett. 37:3005-3016.
Rapisarda, P., S. Fabroni, S. Peterek, G. Russo, and H.-P. Mock. 2009. Juice of new citrus hybrids (Citrus clementina Hort. ex Tan $\times C$. sinensis L. Osbeck) as a source of natural antioxidants. Food Chem. 117:212-218.

Regnault-Roger, C., C. Vincent, and J.T. Arnason. 2012. Essential oils in insect control: Low-risk products in a high-stakes world. Annu. Rev. Entomol. 57:405-424.

Robinson, R.W. and D. Decker-Walters. 1997. Cucurbits. 226 p. CAB International, Wallingford, England.

Rockström, J., L. Karlberg, S.P. Wani, J. Barron, N. Hatibu, T. Oweis, A. Bruggeman, J. Farahani, and Z. Qiang. 2010. Managing water in rainfed agriculture- The need for a paradigm shift. Agr. Water Mgt. 97:543-550

Rockstrom, J., W. Steffen, K. Noone, A. Persson, F.S. Chapin, E.F. Lambin, T.M. Lenton, M. Scheffer, C. Folke, H.J. Schellnhuber, B. Nykvist, C.A. de Wit, T. Hughes, S. van der Leeuw, H. Rodhe, S. Sorlin, P.K. Snyder, R. Costanza, U. Svedin, M. Falkenmark, L. Karlberg, R.W. Corell, V.J. Fabry, J. Hansen, B. Walker, D. Liverman, K. Richardson, P. Crutzen, and J.A. Foley. 2009. A safe operating space for humanity. Nature 461:472-475.

Rohman, A., C. Man, B. Yaakob, and S. Riyanto. 2011. Authentication Analysis of Red Fruit (Pandanus conoideus Lam) oil using FTIR spectroscopy in combination with chemometrics. Phytochem. Anal. 22:462-467.

Römer, S., J. Lübeck, F. Kauder, S. Steiger, C. Adomat, and G. Sandmann. 2002. Genetic engineering of a zeaxanthin-rich potato by antisense inactivation and co-suppression of carotenoid epoxidation. Metab. Eng. 4:263-272.

Ross, A.C., J.E. Manson, S.A. Abrams, J.F. Aloia, P.M. Brannon, S.K. Clinton, R.A. DurazoArvizu, J.C. Gallagher, R.L. Gallo, and G. Jones. 2011. The 2011 report on dietary reference intakes for calcium and vitamin $D$ from the Institute of Medicine: What clinicians need to know. J. Clin. Endocrinol. Metab. 96:53-58.

Sarikamis, G., J. Marquez, R. Maccormack, R. Bennett, J. Roberts, and R. Mithen. 2006. High glucosinolate broccoli: A delivery system for sulforaphane. Mol. Breed. 18:219-228.

Seeman, E., J. Compston, J. Adachi, M.L. Brandi, C. Cooper, B. Dawson-Hughes, B. Jonsson, H. Pols, and J.A. Cramer. 2007. Non-compliance: The Achilles' heel of anti-fracture efficacy. Osteoporos. Intl. 18:711-719.

Shabrova, E.V., O. Tarnopolsky, A.P. Singh, J. Plutzky, N. Vorsa, and L. Quadro. 2011. Insights into the molecular mechanisms of the anti-atherogenic actions of flavonoids in normal and obese mice. PLoS ONE 6:e24634.

Simon, P. W. and I. L. Goldman. 2007. Carrot, p. 497-517. In: Singh, R. J. (ed.), Genetic Resources, Chromosome Engineering, and Crop Improvement: Vegetable Crops. CRC Press, a Taylor \& Francis Group, L.L.C., Boca Raton, FL.

Sloan, A.E. 2006. Top 10 functional food trends. Food Technol. 4(6):23-34.

Šmejkal, K. 2013. Cytotoxic potential of Cprenylated flavonoids. Phytochem. Rev. 1-31.

Smith, C., K.A. Lombard, E.B. Peffley, and W. Liu. 2003. Genetic analysis of quercetin in onion (Allium cepa L.) 'Lady Raider' Tex. J. Agr. Nat. Resour. 16:24-28.

Stobiecki, M., I. Matysiak-Kata, R. Frański, J. Skała, and J. Szopa. 2003. Monitoring changes in anthocyanin and steroid alkaloid glycoside content in lines of transgenic potato plants using liquid chromatography/mass spectrometry. Phytochemistry 62:959-969.
Sun, J., Y.-F. Chu, X. Wu, and R.H. Liu. 2002. Antioxidant and antiproliferative activities of common fruits. J. Agr. Food Chem. 50:74497454.

Thompson, M.D., C. Stushnoff, J.N. McGinley, and H.J. Thompson. 2009. In vitro measures used to predict anticancer activity of apple cultivars and their comparison to outcomes from a rat model of experimentally induced breast cancer. Nutr. Cancer 61:510-517.

Uckoo, R.M., G.K. Jayaprakasha, and B.S. Patil. 2011a. Rapid simultaneous determination of amines and organic acids in citrus using highperformance liquid chromatography. Talanta 83:948-954.

Uckoo, R.M., G.K. Jayaprakasha, and B.S. Patil. 2011b. Rapid separation method of polymethoxyflavones from citrus using flash chromatography. Separ. Purif. Tech. 81:151-158.

Uckoo, R.M., G.K. Jayaprakasha, V.M. Balasubramaniam, and B.S. Patil. 2012a. Grapefruit (Citrus paradisi Macfad) phytochemicals composition is modulated by household processing techniques. J. Food Sci. 77:C921-C926.

Uckoo, R.M., G.K. Jayaprakasha, and B.S. Patil 2012b. Chromatographic Techniques for the Separation of Polymethoxyflavones from Citrus, p. 3-15. In: Patil, B.S., Jayaprakasha, G.K., Murthy, K.N.C., and Seeram, N.P. (eds.), Emerging Trends in Dietary Components for Preventing and Combating Disease. American Chemical Society Symposium Series 1093 .

Uckoo, R.M., G.K. Jayaprakasha, and B.S. Patil. 2013a. Hyphenated flash chromatographic separation and isolation of furocoumarins and polymethoxyflavones from byproduct of citrus juice processing industry. Sep. Sci. Technol. 48:1467-1472.

Uckoo, R.M., G.K. Jayaprakasha, J.A. Somerville, V.M. Balasubramaniam, M. Pinarte, and B.S. Patil. 2013b. High pressure processing controls microbial growth and minimally alters the levels of health promoting compounds in grapefruit (Citrus paradisi Macfad) juice. Innov. Food Sci. Emerg. Technol. 18:7-14.

Uusi-Rasi, K., M.U. Kärkkäinen, and C.J. LambergAllardt. 2013. Calcium intake in health maintenance-A systematic review. Food \& nutrition research 57.

van Jaarsveld, P.J., M. Faber, S.A. Tanumihardjo, P. Nestel, C.J. Lombard, and A.J.S. Benadé. 2005. $\beta$-Carotene-rich orange-fleshed sweet potato improves the vitamin A status of primary school children assessed with the modified-relative-dose-response test. Amer. J. Clin. Nutr. 81:1080-1087.

Varshney, R.K., D.A. Hoisington, S.N. Nayak, and A. Graner. 2009. of Conference. Molecular Plant breeding: Methodology and achievements, conference location date. Methods Mol. Biol. 513.

Verkler, E. 2006. No bones about it: AAP report says calcium a vital part of children's diets (AAP News). The Official Newsmagazine of The American Academy of Pediatrics 27:20.

Victora, C.G., M. de Onis, P.C. Hallal, M. Blössner, and R. Shrimpton. 2010. Worldwide timing of growth faltering: Revisiting implications for interventions. Pediatrics 125:e473-e480.

Vikram, A., G.K. Jayaprakasha, and B.S. Patil 2007. Simultaneous determination of citrus limonoid aglycones and glucosides by high performance liquid chromatography. Anal. Chim. Acta 590:180-186.

Vikram, A., G.K. Jayaprakasha, R.M. Uckoo, and B.S. Patil. 2013. Inhibition of Escherichia coli O157:H7 motility and biofilm by $\beta$-Sitosterol 
glucoside. Biochimica et Biophysica Acta (BBA) - General subjects. 1830:5219-5228.

Vizzotto, M., L. Cisneros-Zevallos, D.H. Byrne, D.W. Ramming, and W. Okie. 2007. Large variation found in the phytochemical and antioxidant activity of peach and plum germplasm. J. Amer. Soc. Hort. Sci. 132: 334-340.

Vorsa, N. and J.J. Polashock. 2005. Alteration of anthocyanin glycosylation in cranberry through interspecific hybridization. J. Amer. Soc. Hort. Sci. 130:711-715.

Wareham, N.J., E.M. van Sluijs, and U. Ekelund. 2005. Symposium on 'Prevention of Obesity'; Physical activity and obesity prevention: A review of the current evidence. Proc. Nutr. Soc. 64:229-247.

Wargovich, M., J. Morris, V. Moseley, R. Weber, and D.H. Byrne. 2012. Developing Fruit Cultivars with Enhanced Health Properties, p. 37-68. In: Badenes, M.L. and Byrne, D.H. (eds.), Fruit Breeding. Springer, New York, US.
Weaver, C.M., W.R. Proulx, and R. Heaney. 1999. Choices for achieving adequate dietary calcium with a vegetarian diet. Amer. J. Clin. Nutr. 70:543S-548.

Weil, J.-H. 2005. Are genetically modified plants useful and safe? IUBMB Life 57:311314.

Wells, H.F. and J.C. Buzby. 2008. Dietary assessment of major trends in U. S. food consumption, 1970-2005. Economic Information Bulletin No. 33 Economic Research Service, U. S. Dept. of Agriculture, Economic Research Service. Washington, D.C.

White, P.J. and M.R. Broadley. 2009. Biofortification of crops with seven mineral elements often lacking in human diets-Iron, zinc, copper, calcium, magnesium, selenium and iodine. New Phytol. 182:49-84.

Winzenberg, T., K. Shaw, J. Fryer, and G. Jones. 2006. Effects of calcium supplementation on bone density in healthy children: Metaanalysis of randomised controlled trials. BMJ $333: 775$.
Wojdyło, A., J. Oszmiański, and P. Laskowski. 2008. Polyphenolic compounds and antioxidant activity of new and old apple varieties. J. Agr. Food Chem. 56:6520-6530.

Wolfe, K., X. Wu, and R.H. Liu. 2003. Antioxidant activity of apple peels. J. Agr. Food Chem. 51:609-614.

Wootton-Beard, P.C. and L. Ryan. 2011. Improving public health?: The role of antioxidant-rich fruit and vegetable beverages. Food Res. Intl. 44:3135-3148.

Yang, J., T. Punshon, M.L. Guerinot, and K.D. Hirschi. 2012. Plant calcium content: Ready to remodel. Nutrients 4:1120-1136.

Yi, W., J. Fischer, G. Krewer, and C.C. Akoh. 2005. Phenolic compounds from blueberries can inhibit colon cancer cell proliferation and induce apoptosis. J. Agr. Food Chem. 53:7320-7329.

Yoshizawa, Y., K. Sakurai, S. Kawaii, M. Asari, J. Soejima, and N. Murofushi. 2005. Comparison of antiproliferative and antioxidant properties among nineteen apple cultivars. HortScience 40:1204-1207. 